Article

\title{
Synthesis of Isotactic-block-Syndiotactic Poly(methyl Methacrylate) via Stereospecific Living Anionic Polymerizations in Combination with Metal-Halogen Exchange, Halogenation, and Click Reactions
}

\author{
Naoya Usuki ${ }^{1}$, Kotaro Satoh ${ }^{1,2, *}$ and Masami Kamigaito ${ }^{1, *}$ \\ 1 Department of Molecular and Macromolecular Chemistry, Graduate School of Engineering, \\ Nagoya University, Furo-cho, Chikusa-ku, Nagoya 464-8603, Japan; usuki@chiral.apchem.nagoya-u.ac.jp \\ 2 Precursory Research for Embryonic Science and Technology, Japan Science and Technology Agency, \\ 4-1-8 Honcho, Kawaguchi, Saitama 332-0012, Japan \\ * Correspondence: satoh@chembio.nagoya-u.ac.jp (K.S.), kamigait@chembio.nagoya-u.ac.jp (M.K.); \\ Tel.: +81-52-789-5400 (M.K.)
}

Received: 23 November 2017; Accepted: 14 December 2017; Published: 16 December 2017

\begin{abstract}
Isotactic (it-) and syndiotactic (st-) poly(methyl methacrylate)s (PMMAs) form unique crystalline stereocomplexes, which are attractive from both fundamental and application viewpoints. This study is directed at the efficient synthesis of it- and st-stereoblock (it-b-st-) PMMAs via stereospecific living anionic polymerizations in combination with metal-halogen exchange, halogenation, and click reactions. The azide-capped it-PMMA was prepared by living anionic polymerization of MMA, which was initiated with $t-\mathrm{BuMgBr}$ in toluene at $-78{ }^{\circ} \mathrm{C}$, and was followed by termination using $\mathrm{CCl}_{4}$ as the halogenating agent in the presence of a strong Lewis base and subsequent azidation with $\mathrm{NaN}_{3}$. The alkyne-capped st-PMMA was obtained by living anionic polymerization of MMA, which was initiated via an in situ metal-halogen exchange reaction between 1,1-diphenylhexyl lithium and an $\alpha$-bromoester bearing a pendent silyl-protected alkyne group. Finally, copper-catalyzed azide-alkyne cycloaddition (CuAAC) between these complimentary pairs of polymers resulted in a high yield of it-b-st-PMMAs, with controlled molecular weights and narrow molecular weight distributions. The stereocomplexation was evaluated in $\mathrm{CH}_{3} \mathrm{CN}$ and was affected by the block lengths and ratios.
\end{abstract}

Keywords: living polymerization; stereospecific polymerization; anionic polymerization; methyl methacrylate; PMMA; stereoblock polymer; stereocomplex; click reaction; isotactic polymer; syndiotactic polymer

\section{Introduction}

Recent advances in controlled polymerizations, including living and stereospecific polymerizations, as well as highly efficient reactions, such as click reactions, enable the synthesis of various architecturally controlled polymers [1]. In addition, an alternative and more efficient synthetic route for polymer structures can be created by these developments, which is the case in the synthesis of organic molecules, such as medicines and natural products due to the development of new reactions.

Typical stereoregular poly(methyl methacrylate)s (PMMAs), i.e., isotactic (it-) and syndiotactic (st-) PMMAs, are known to associate in the solid state and specific solutions to form a crystalline polymer complex, i.e., a stereocomplex, in which inner single or double helixes of the it-PMMA chain are surrounded by an outer st-PMMA helical chain with a larger radius [2-10]. The unique structures and properties of synthetic polymers have attracted attention from both fundamental and application viewpoints [11-19]. Furthermore, these stereoregular polymer chains have been incorporated into 
various well-defined polymers, such as block, star, graft, and end-functionalized polymers, to create novel properties and functions [20-39].

Stereoblock PMMAs that consist of it- and st-PMMA blocks connected in one linear chain have been prepared via various approaches. Although there have been several reports on the formation of $i t-b$-st-stereoblock PMMAs via anionic polymerization under certain conditions since the 1950s, they are mostly mixtures of it- and st-PMMAs or are randomly segmented itand st-PMMA blocks with uncontrolled block lengths and broad molecular weight distributions (MWDs) [3,40-49]. The well-defined it-b-st-stereoblock PMMA was first synthesized in 1986 via a sequential living anionic block copolymerization of two monomers, diphenylmethyl and triphenylmethyl methacrylates, which resulted in syndiotactic $(r r=84 \%)$ and isotactic $(m m=91 \%)$ sequences, respectively, followed by hydrolysis and methylation of their ester moieties [22]. Later, the direct synthesis of an it-b-st-stereoblock PMMA was achieved via the transformation of the isotactic living anionic polymerization of MMA, initiated with $t$ - $\mathrm{BuMgBr}$ in toluene at $-60{ }^{\circ} \mathrm{C}(\mathrm{mm}=96 \%)$ into a syndiotacitc polymerization via the addition of $\mathrm{Me}_{3} \mathrm{Al}$ at a ratio of $\mathrm{Al} / \mathrm{Mg} \geq 6$ at $-78{ }^{\circ} \mathrm{C}$ $(r r \leq 75 \%)$ [23]. Another synthetic route to synthesize it-b-st-stereoblock PMMA was reported via a coupling reaction between the alcohol-capped $i t$ - $(m m=97 \%)$ and $s t$-PMMAs $(r r=89 \%)$ by sebacoyl dichloride, where the two prepolymers were prepared by living anionic polymerizations of MMA with $t$-BuMgBr and $t$-BuLi $/ n$-Bu $3 \mathrm{Al}$, respectively, in toluene at $-78{ }^{\circ} \mathrm{C}$ followed by termination with allyliodide and a subsequent hydroboration-oxidation [24-27]. This approach was further used for the synthesis of uniform $i t-b$-st-stereoblock PMMA with a single molecular weight via fractionation using preparative size-exclusion chromatography (SEC) and supercritical fluid chromatography (SFC). The stereocomplexation behavior was analyzed in detail. However, this coupling reaction statistically results in 50\% homo-coupling products (it-b-it and st-b-st), which should be separated from the desired hetero-coupling products by chromatography. A more efficient synthetic approach can be developed by designing polymerization and coupling reactions.

We have recently determined that the halogenation of the growing enolate terminal in the isotactic and syndiotactic living anionic polymerization of MMA is efficient and feasible upon the addition of $\mathrm{CCl}_{4}$ or $\mathrm{CCl}_{3} \mathrm{Br}$ in the presence of a strong Lewis base, such as 1,8-diazabicyclo[5,4,0]undec-7-ene (DBU) [50]. Furthermore, the halogen terminal of PMMA can be almost quantitatively transformed into an azide terminal via a reaction with sodium azide [33,36]. In addition, an alkyne-capped PMMA can be synthesized by a living anionic polymerization of MMA that is initiated via an in situ metal-halogen exchange reaction between 1,1-diphenylhexyl lithium, i.e., the sacrificial anion source, and an $\alpha$-haloester bearing a pendent silyl-protected alkyne group, i.e., a precursor of the functionalized initiator [36]. In our previous report, both $\alpha$-alkyne and $\omega$-azide chain-end functionalizations were used in a single polymer chain of st-PMMA to enable the synthesis of cyclic st-PMMA. Here, we report a more efficient synthesis of it-b-st-stereoblock PMMA via a copper-catalyzed azide-alkyne cycloaddition (CuAAC) between azide- $\omega$-capped it-PMMA and alkyne- $\alpha$-capped st-PMMA, prepared via a stereospecific anionic polymerization (Scheme 1). 


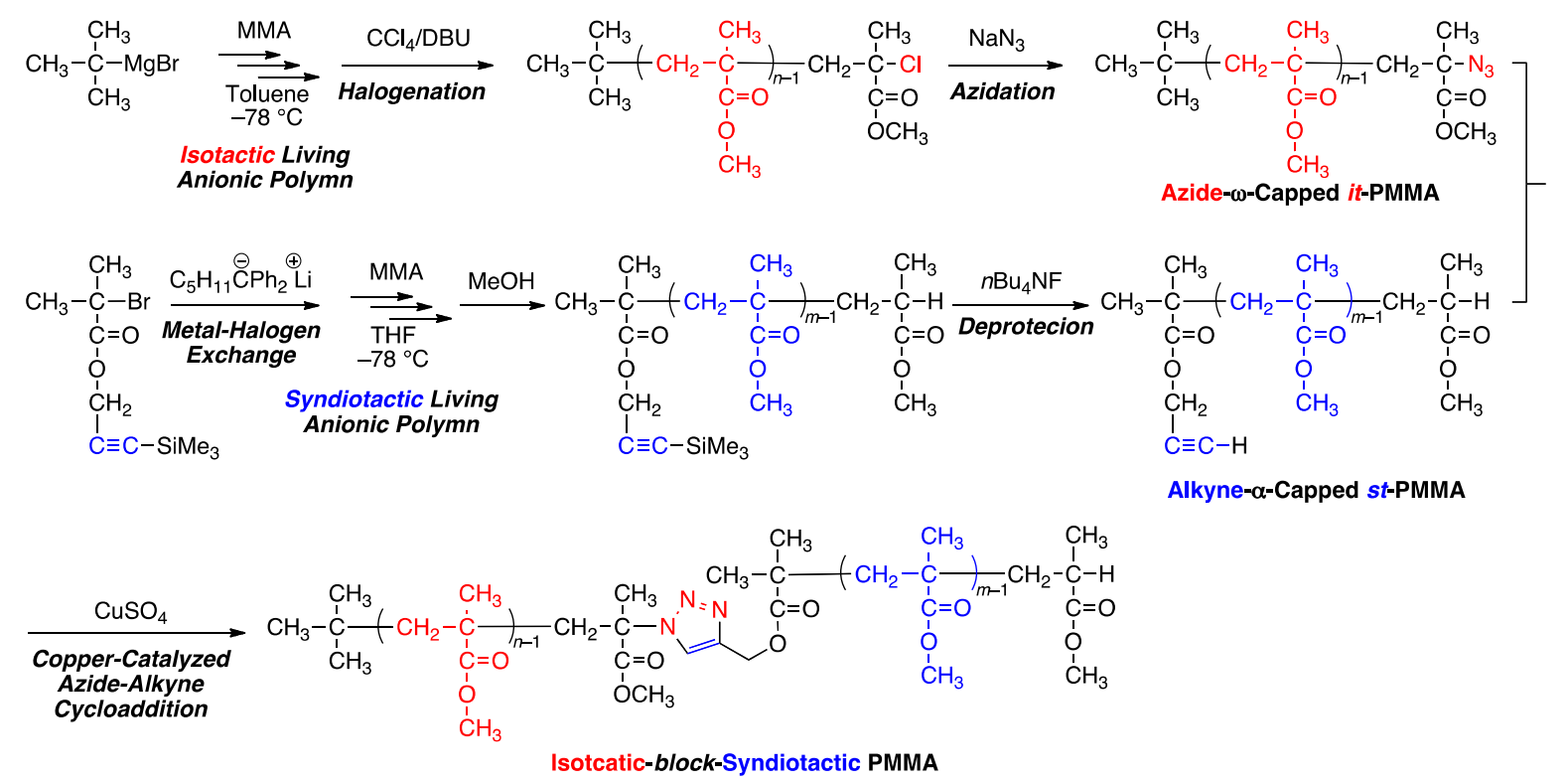

Scheme 1. Synthesis of Isotactic-block-Syndiotactic Poly(methyl Methacrylate) via Stereospecific Living Anionic Polymerizations in Combination with Metal-Halogen Exchange, Halogenation, and Click Reactions.

\section{Materials and Methods}

\subsection{Materials}

Methyl methacrylate (MMA; TCI, Tokyo, Japan, >99.8\%), 1,8-diazabicyclo[5.4.0]undec-7-ene (DBU; TCI, Tokyo, Japan, >98.0\%), and $\mathrm{CCl}_{4}$ (Kanto, Tokyo, Japan, $>99.9 \%$ ) were distilled from calcium hydride before use. $t$-BuMgBr, diphenylhexyllithium (DPHLi), and 3-(trimethylsilyl)propargyl $\alpha$-bromoisobutyrate (1) were prepared according to the literature [36,50-53]. Toluene (Kanto, Tokyo, Japan, >99.5\%; $\mathrm{H}_{2} \mathrm{O}<0.001 \%$ ) and tetrahydrofuran (THF; Kanto, >99.5\%; $\mathrm{H}_{2} \mathrm{O}<0.001 \%$ ) were dried and deoxygenized by passage through columns of Glass Contour Solvent Systems (Glass Contour, Nashua, $\mathrm{NH}, \mathrm{USA})$ before use. Tetrabutylammonium fluoride ( $n-\mathrm{Bu}_{4} \mathrm{NF}$; TCI, Tokyo, Japan, ca. $1 \mathrm{~mol} / \mathrm{L}$ in THF), sodium azide $\left(\mathrm{NaN}_{3}\right.$; TCI, Tokyo, Japan, >99.0\%), $\mathrm{CuSO}_{4}$ (Kanto, Tokyo, Japan, >97.5\%), ascorbic acid (TCI, Tokyo, Japan, >99.0\%), sodium ascorbate (Kanto, Tokyo, Japan, >98.0\%), $\mathrm{CH}_{3} \mathrm{CN}$ (Kanto, Tokyo, Japan, 99.5\%), and DMSO (Kanto, Tokyo, Japan, 99.5\%) were used as received. CuCl (Aldrich, St. Louis, MO, USA, 99.99\%), $\mathrm{CuCl}_{2}$ (Aldrich, St. Louis, MO, USA, 99.99\%) and 2,2'-bipyridyl (bpy; Aldrich, St. Louis, MO, USA, $>99.0 \%$ ) was used as received and was handled in a glove box (MBRAUN LABmaster sp, Garching, Germany) under a moisture and oxygen-free argon atmosphere $\left(\mathrm{O}_{2},<1 \mathrm{ppm}\right)$.

\subsection{Synthesis of Azide-w-Capped it-PMMA via Isotactic Living Anionic Polymerization of MMA Followed by} Termination with Halogenation and Subsequent Azidation

The reactions were carried out by syringe techniques under dry argon in a $100 \mathrm{~mL}$ baked glass tube equipped with a three-way stopcock. The following is a typical example for it-50-PMMA. The polymerization was initiated by adding MMA $(5.2 \mathrm{~mL}, 49 \mathrm{mmol})$ slowly via a dry syringe into the prechilled initiator solution $(31 \mathrm{~mL})$, containing $t$-BuMgBr $\left(0.97 \mathrm{mmol}, 3.5 \mathrm{~mL}, 276 \mathrm{mM}\right.$ in $\left.\mathrm{Et}_{2} \mathrm{O}\right)$ and toluene $(27 \mathrm{~mL})$, at $-78{ }^{\circ} \mathrm{C}$. The total volume of the reaction mixture was thus $36 \mathrm{~mL}$. After stirring for $26 \mathrm{~h}$, the THF solution $(56 \mathrm{~mL})$ of $\mathrm{CCl}_{4}(44 \mathrm{mmol}, 4.3 \mathrm{~mL})$ and DPHLi $(3.4 \mathrm{mmol}, 8.4 \mathrm{~mL}, 400 \mathrm{mM}$ in THF) was added to the reaction mixture. After $1 \mathrm{~h}$, into the reaction mixture was then added DBU $(9.7 \mathrm{mmol}, 1.5 \mathrm{~mL})$ and the reaction temperature was gradually raised to $0^{\circ} \mathrm{C}$. After additional $24 \mathrm{~h}$, the reaction was quenched by $6.8 \mathrm{~mL}$ of argon-bubbled methanol. The quenched solution was diluted with $100 \mathrm{~mL}$ of toluene and was washed with diluted hydrochloric acid and water, 
evaporated to dryness under reduced pressure, and then vacuum-dried to give the product $\left(M_{n}=5000\right.$, $M_{\mathrm{w}} / M_{\mathrm{n}}=1.50$ ) containing low molecular weight residues. The obtained product was dissolved with toluene and reprecipitated into hexane three times to result in the chlorine-capped it-PMMA $\left(M_{\mathrm{n}}=5100, M_{\mathrm{W}} / M_{\mathrm{n}}=1.61, \mathrm{~mm} / \mathrm{mr} / \mathrm{rr}=92 / 7 / 1\right)$.

The obtained chlorine-capped it-PMMA (1.0 g, $0.20 \mathrm{mmol})$, sodium azide (130 mg, $2.0 \mathrm{mmol})$, and ascorbic acid $(5.3 \mathrm{mg}, 0.030 \mathrm{mmol})$ were dissolved in $20 \mathrm{~mL}$ of $\mathrm{CH}_{3} \mathrm{CN} / \mathrm{H}_{2} \mathrm{O}$ (9:1). A catalyst solution of $\mathrm{CuCl} / \mathrm{CuCl}_{2} /$ bpy $\left(0.10 / 0.067 / 0.33 \mathrm{M}\right.$ in $\left.\mathrm{CH}_{3} \mathrm{CN} / \mathrm{H}_{2} \mathrm{O}(9: 1), 1.19 \mathrm{~mL}\right)$ was then added. The flask was immersed in thermostatic oil bath at $40{ }^{\circ} \mathrm{C}$ and kept stirred for $18 \mathrm{~h}$. The solution was diluted with $50 \mathrm{~mL}$ of toluene, and washed with diluted hydrochloric acid and water. The solution was concentrated and dried to give the azide- $\omega$-ended it-PMMA $\left(M_{n}=4800, M_{\mathrm{w}} / M_{\mathrm{n}}=1.59\right)$.

\subsection{Synthesis of Alkyne- $\alpha$-Capped st-PMMA via Syndiotactic Living Anionic Polymerization of MMA Initiated via a Metal-Halogen Exchange Reaction}

The reactions were carried out by syringe techniques under dry argon in a $100 \mathrm{~mL}$ baked glass tube equipped with a three-way stopcock. The following is a typical example for st-50-PMMA. Prior to the polymerization, the functionalized enolate initiator was in situ prepared by adding $6.4 \mathrm{~mL}$ of 1 $\left(1.7 \mathrm{mmol}, 272 \mathrm{mM}\right.$ in THF) into the THF solution $(40 \mathrm{~mL})$ of DPHLi $(2.6 \mathrm{mmol})$ at $-100^{\circ} \mathrm{C}$. Into the mixture, MMA ( $48 \mathrm{mmol}, 5.1 \mathrm{~mL}$ ) was added dropwise, and the total volume of the reaction mixture was thus $52 \mathrm{~mL}$. After stirring for $30 \mathrm{~min}$, the polymerization was terminated with acidic methanol $(4.5 \mathrm{~mL})$. The solution was diluted with $100 \mathrm{~mL}$ toluene, and was washed with diluted hydrochloric acid and water, evaporated to dryness under reduced pressure, and then vacuum-dried to give the product $\left(M_{\mathrm{n}}=6300, M_{\mathrm{W}} / M_{\mathrm{n}}=1.11, \mathrm{~mm} / \mathrm{mr} / \mathrm{rr}=1 / 22 / 77\right)$.

The obtained st-PMMA with a protected alkyne $(3.4 \mathrm{~g}, 0.63 \mathrm{mmol})$ was dissolved in $58 \mathrm{~mL}$ of THF. To the solution, $1.3 \mathrm{~mL}$ of the THF solution of $n-\mathrm{Bu}_{4} \mathrm{NF}(1.0 \mathrm{M}, 1.3 \mathrm{mmol})$ was added at $0{ }^{\circ} \mathrm{C}$. After 1 $\mathrm{h}$, the solution was diluted with $30 \mathrm{~mL}$ of toluene, washed with diluted hydrochloric acid and water, and evaporated to dryness to the alkyne- $\alpha$-ended st-PMMA $\left(M_{\mathrm{n}}=6100, M_{\mathrm{w}} / M_{\mathrm{n}}=1.11\right)$.

\subsection{Synthesis of it-b-st-Stereoblock PMMA via Copper-Catalyzed Azide-Alkyne Cycloaddition}

The $\mathrm{CuAAc}$ reaction was carried out with $\mathrm{CuSO}_{4}$ in the presence of sodium ascorbate as the reducing agent in DMSO/ $\mathrm{H}_{2} \mathrm{O}(98 / 2)$ in a baked glass tube equipped with a three-way stopcock. The following is a typical example for it-50-b-st-100-PMMA. The azide- $\omega$-ended it-PMMA $\left(M_{\mathrm{n}}=4800\right.$, $\left.M_{\mathrm{w}} / M_{\mathrm{n}}=1.59, F_{\mathrm{n}}\left(\mathrm{N}_{3}\right)=0.74,247 \mathrm{mg}, 0.051 \mathrm{mmol}\right)$ and alkyne- $\alpha$-ended $s t$-PMMA $\left(M_{\mathrm{n}}=12000\right.$, $\left.M_{\mathrm{w}} / M_{\mathrm{n}}=1.11, F_{\mathrm{n}}(\mathrm{C} \equiv \mathrm{C}-\mathrm{H})=1.04,462 \mathrm{mg}, 0.039 \mathrm{mmol}\right)$ were dissolved in DMSO (1.9 mL). To this solution, $0.04 \mathrm{~mL}$ of $\mathrm{H}_{2} \mathrm{O}, \mathrm{CuSO}_{4}(2.1 \mathrm{mg}, 0.013 \mathrm{mmol})$, and sodium ascorbate $(10 \mathrm{mg}, 0.051 \mathrm{mmol})$ were added. The flask was immersed in thermostatic oil bath at $70{ }^{\circ} \mathrm{C}$, and the reaction mixture was allowed to stir for $24 \mathrm{~h}$. The reaction was quenched by dilution with toluene $(50 \mathrm{~mL})$. The mixture was washed with diluted hydrochloric acid and water. The solution was evaporated to dryness under reduced pressure in order to give the crude stereoblock PMMA $\left(M_{n}=12400, M_{\mathrm{w}} / M_{\mathrm{n}}=1.20\right)$. The obtained product was dissolved in toluene and reprecipitated into hexane three times to result in the it-50-b-st-100-PMMA $\left(M_{\mathrm{n}}=14000, M_{\mathrm{w}} / M_{\mathrm{n}}=1.20\right)$.

\subsection{Measurements}

The number-average molecular weight $\left(M_{n}\right)$ and molecular weight distribution $\left(M_{\mathrm{w}} / M_{\mathrm{n}}\right)$ of the polymers were measured by size-exclusion chromatography (SEC) using THF at a flow rate $1.0 \mathrm{~mL} / \mathrm{min}$ at $40^{\circ} \mathrm{C}$ on two polystyrene gel columns (Shodex KF-805L (Showa Denko K.K., Tokyo, Japan, pore size: $20-1000 \AA ; 8.0 \mathrm{~mm}$ i.d. $\times 30 \mathrm{~cm}$ )) that were connected to a JASCO PU-2080 precision pump and a JASCO RI-2031 detector (JASCO, Tokyo, Japan). The columns were calibrated against seven standard PMMA samples (Agilent Technologies, Santa Clara, CA, USA; $M_{p}=202-1677000$, $\left.M_{\mathrm{w}} / M_{\mathrm{n}}=1.02-1.23\right) .{ }^{1} \mathrm{H}$ and ${ }^{13} \mathrm{C}$ NMR spectra were recorded on a JEOL ESC-400 spectrometer (JEOL, Tokyo, Japan) operating at 400 and $100 \mathrm{MHz}$, respectively. The triad tacticity of the polymer was 
determined by the peak intensity of carbonyl $\mathrm{C}=\mathrm{O}$ carbons that were observed at $175-180 \mathrm{ppm}$ in the ${ }^{13} \mathrm{C}$ NMR spectrum. The transmittance of polymer solutions was recorded in $\mathrm{CH}_{3} \mathrm{CN}$ using a JASCO V-550 spectrophotometer (JASCO, Tokyo, Japan) (cooling rate $=1^{\circ} \mathrm{C} / \mathrm{min}$; wavelength $500 \mathrm{~nm}$ ). The glass transition $\left(T_{\mathrm{g}}\right)$ and melting $\left(T_{\mathrm{m}}\right)$ temperatures were recorded on Q200 differential scanning calorimeter (DSC) (TA Instruments Inc., New Castle, DE, USA). $T_{\mathrm{g}}$ was obtained form the second scan, where the samples were heated to $180{ }^{\circ} \mathrm{C}$ at $10^{\circ} \mathrm{C} / \mathrm{min}$, equilibrated at $180^{\circ} \mathrm{C}$ for $5 \mathrm{~min}$, cooled to $0{ }^{\circ} \mathrm{C}$ at $5{ }^{\circ} \mathrm{C} / \mathrm{min}$, held at $0{ }^{\circ} \mathrm{C}$ for $5 \mathrm{~min}$, and then reheated to $200{ }^{\circ} \mathrm{C}$ at $10{ }^{\circ} \mathrm{C} / \mathrm{min}$. $T_{\mathrm{m}}$ was obtained from the first scan, where the samples were heated from 40 to $250{ }^{\circ} \mathrm{C}$ at $10^{\circ} \mathrm{C} / \mathrm{min}$. The samples for $T_{\mathrm{m}}$ were obtained by evaporating $\mathrm{CH}_{3} \mathrm{CN}$ from the solution of stereoblock PMMA (50 mg/mL) and dried under vacuo overnight.

\section{Results and Discussion}

3.1. Synthesis of Azide- $\omega$-Capped it-PMMA via Isotactic Living Anionic Polymerization of MMA Followed by Termination with Halogenation and Subsequent Azidation

Isotactic living anionic polymerization of MMA was conducted with $t$ - $\mathrm{BuMgBr}$ in toluene at $-78{ }^{\circ} \mathrm{C}[51,52]$ at different molar ratios $\left([\mathrm{M}]_{0} /[t-\mathrm{BuMgBr}]_{0}=25\right.$ and 50$)$ to synthesize $i t$-PMMA with different molecular weights. The polymers obtained after quenching the reaction with acidic methanol had controlled molecular weights and narrow MWDs, as shown in the SEC curves (Figure 1A,E). The ${ }^{13} \mathrm{C}$ NMR showed isotactic-rich enchainments $(\mathrm{mm} / \mathrm{mr} / \mathrm{rr}=91 / 7 / 2$ or $92 / 7 / 1)$, as reported [51,52]. The termination with $\mathrm{CCl}_{4}$ as the chlorinating agent in the presence of DBU, a strong Lewis base, also resulted in polymers with similar molecular weights and narrow MWDs [50]. Although higher and lower molecular weight fractions were slightly observed, probably being due to high viscosity upon quenching (Figure 1B,F), the SEC curves were nearly unimodal after the reprecipitations (Figure 1C,G). 

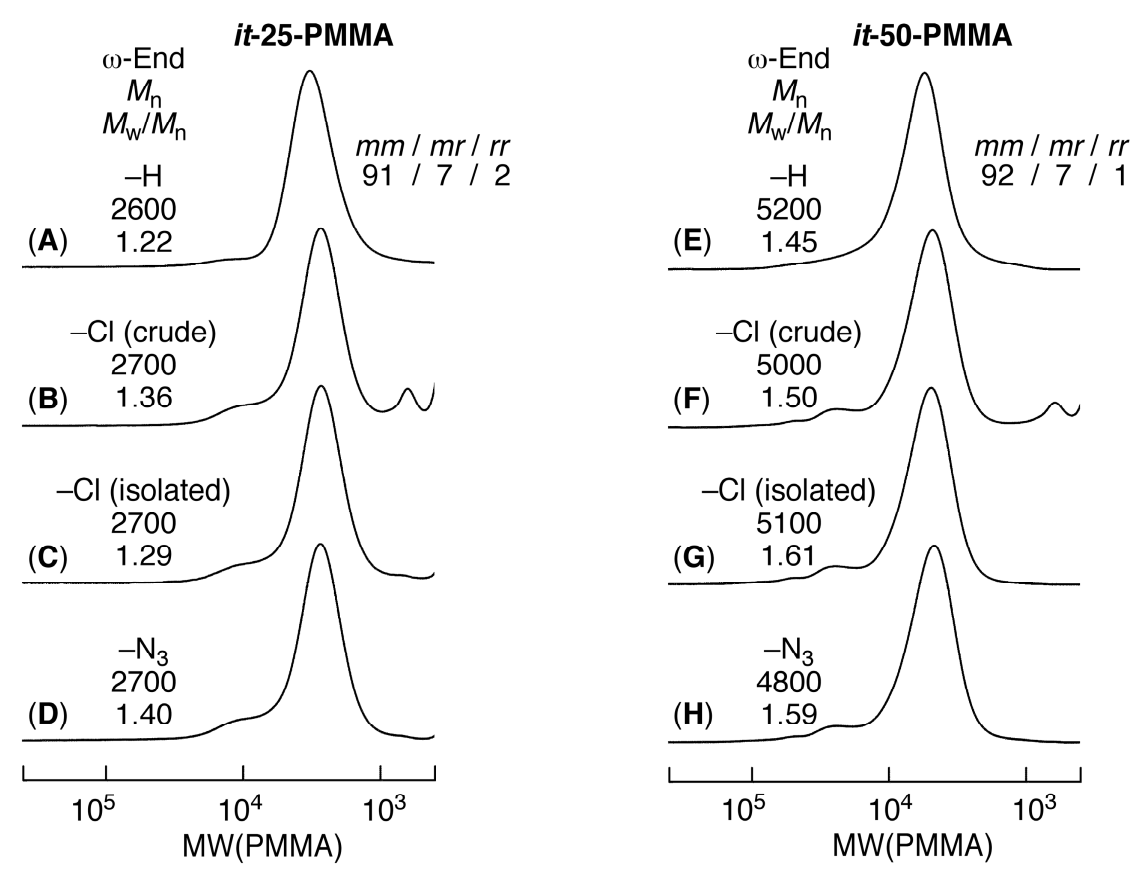

Figure 1. Size-exclusion chromatography (SEC) curves of a series of $i t$ - poly(methyl methacrylate)s (PMMAs) ((A-D): it-25, (E-H): it-50) obtained in isotactic anionic polymerization of Methyl methacrylate (MMA) with $t$-BuMgBr in toluene at $-78{ }^{\circ} \mathrm{C}$ and subsequent procedures: (A,E) Quenching the polymerization $\left([\mathrm{M}]_{0} /[t-\mathrm{BuMgBr}]_{0}=1350 / 54\right.$ or $\left.1350 / 27 \mathrm{mM}\right)$ with acidic methanol; $(\mathbf{B}, \mathbf{F})$ Quenching the polymerization with $\mathrm{CCl}_{4} / \mathrm{DBU}\left([\mathrm{M}]_{0} /[t-\mathrm{BuMgBr}]_{0} /\left[\mathrm{CCl}_{4}\right]_{\mathrm{add}} /[\mathrm{DBU}]_{\mathrm{add}}=\right.$ 1350/54/2160/540 or 1350/27/1080/270 mM); (C,G) Reprecipitations; (D,H) Azidation with $\mathrm{NaN}_{3} / \mathrm{CuCl} / \mathrm{CuCl}_{2} /$ bpy in $\mathrm{CH}_{3} \mathrm{CN} / \mathrm{H}_{2} \mathrm{O}=9 / 1$ at $40{ }^{\circ} \mathrm{C}\left(\left[-\mathrm{Cl}_{0} /\left[\mathrm{NaN}_{3}\right]_{0} /[\mathrm{CuCl}]_{0} /\left[\mathrm{CuCl}_{2}\right]_{0} /[\mathrm{bpy}]_{0}\right.\right.$ $=10 / 100 / 6.5 / 4.3 / 22 \mathrm{mM})$.

The ${ }^{1} \mathrm{H}$ NMR spectrum of the polymers obtained by termination with $\mathrm{CCl}_{4}$ shows new peaks, $a_{2}$ and $c_{2}$, which are assignable to the terminal methyl ester and methylene protons that are adjacent to the chloride chain end, respectively (Figure $2 \mathrm{~B}$ ). The terminal chloride functionality $\left(F_{\mathrm{n}}(\mathrm{Cl})\right.$ ) was determined by the ratio of $M_{\mathrm{n}}(\mathrm{SEC})$, as measured by SEC based on the PMMA calibration to $M_{\mathrm{n}}(\mathrm{NMR})$, which was obtained from the peak intensity ratio of $c_{2}$ to the methyl ester protons $(c)$ of the repeating MMA units. The obtained $F_{n}(\mathrm{Cl})$ values were 1.00 and 0.81 for $M_{n}=2700$ and 5100, respectively. In addition, the $F_{\mathrm{n}}(\mathrm{Cl})$ values that were calculated from the peak area ratio of the $\omega$-end methyl ester $\left(c_{2}\right)$ to the $\alpha$-end $t$-butyl $(d)$ protons were 1.00 and 0.78 , respectively. These results indicate that most of the isotactic living chain ends of the PMMAs were capped with chlorine.

The chlorine $\omega$-chain-end polymers were then reacted with $\mathrm{NaN}_{3}$ in the presence of copper catalysts in $\mathrm{CH}_{3} \mathrm{CN} / \mathrm{H}_{2} \mathrm{O}=9 / 1$ at $40{ }^{\circ} \mathrm{C}$. The SEC curve of the polymers that were obtained after azidation showed similarly narrow MWDs (Figure 1D,H). The terminal methylene peak $\left(a_{2}\right)$ clearly shifted upfield $\left(a_{3}\right)$ via the transformation from a chloride into an azide terminal (Figure 2C). The chain-end functionality of the azide group $\left(F_{\mathrm{n}}\left(\mathrm{N}_{3}\right)\right)$ was similarly calculated by the ratio of $M_{\mathrm{n}}(\mathrm{SEC})$ to $M_{\mathrm{n}}(\mathrm{NMR})$, which was obtained from the peak intensity ratio of the methyl ester protons, $c_{3}$ and $c$. The $F_{\mathrm{n}}\left(\mathrm{N}_{3}\right)$ values were 1.00 and 0.74 for $M_{\mathrm{n}}=2700$ and 4800 , respectively. In addition, similar values were obtained from the peak area ratio of the $\omega$-end methyl ester $\left(c_{3}\right)$ to the $\alpha$-end $t$-butyl $(d)$ protons were 0.96 and 0.75 , respectively. They were close to those for $F_{\mathrm{n}}(\mathrm{Cl})$ and indicated that the chloride terminal was almost quantitatively converted into the azide terminal. These results indicate that the it-PMMA with an azide group at the $\omega$-chain end was successfully obtained by isotactic living anionic polymerization of MMA, followed by chlorination for quenching and subsequent azidation. 


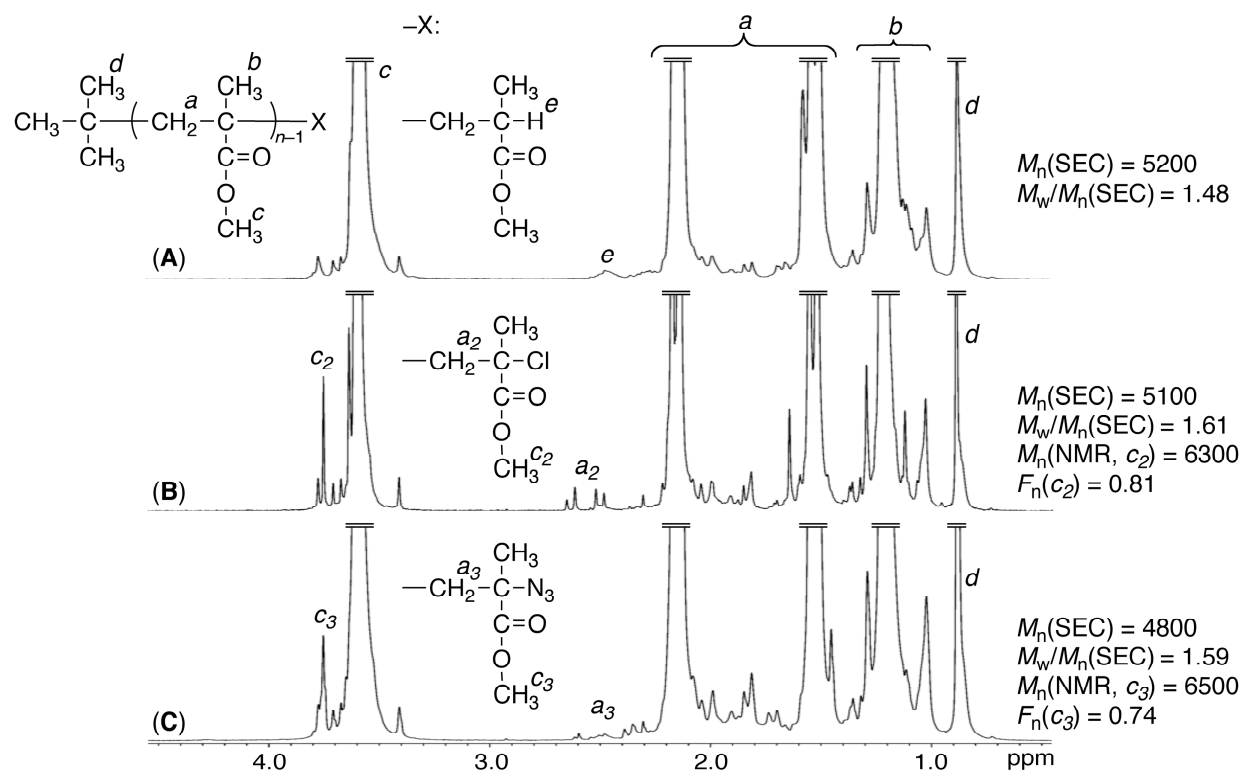

Figure 2. ${ }^{1} \mathrm{H}$ NMR spectra (in $\mathrm{CDCl}_{3}$ at $55{ }^{\circ} \mathrm{C}$ ) of it-50-PMMAs obtained in anionic polymerization of MMA with $t$-BuMgBr in toluene at $-78{ }^{\circ} \mathrm{C}$ and subsequent procedures: (A) Quenching the polymerization $\left([\mathrm{M}]_{0} /[t-\mathrm{BuMgBr}]_{0}=1350 / 27\right)$ with acidic methanol; (B) Quenching the polymerization with $\mathrm{CCl}_{4} / \mathrm{DBU}\left([\mathrm{M}]_{0} /[t-\mathrm{BuMgBr}]_{0} /\left[\mathrm{CCl}_{4}\right]_{\text {add }} /[\mathrm{DBU}]_{\text {add }}=1350 / 27 / 1080 / 270\right)$ followed by reprecipitations; (C) Azidation with $\mathrm{NaN}_{3} / \mathrm{CuCl} / \mathrm{CuCl}_{2} /$ bpy in $\mathrm{CH}_{3} \mathrm{CN} / \mathrm{H}_{2} \mathrm{O}=9 / 1$ at $40{ }^{\circ} \mathrm{C}\left(\left[-\mathrm{Cl}_{0} /\left[\mathrm{NaN}_{3}\right]_{0} /[\mathrm{CuCl}]_{0} /\left[\mathrm{CuCl}_{2}\right]_{0} /[\mathrm{bpy}]_{0}=10 / 100 / 6.5 / 4.3 / 22 \mathrm{mM}\right)\right.$.

\subsection{Synthesis of Alkyne- $\alpha$-Capped st-PMMA via Syndiotactic Living Anionic Polymerization of MMA} Initiated via a Metal-Halogen Exchange Reaction

To synthesize the alkyne-capped functionalized st-PMMA, syndiotactic living anionic polymerization of MMA was initiated via a metal-halogen exchange reaction between 1,1-diphenylhexyl lithium (DPHLi) and an $\alpha$-bromoisobutyric acid ester bearing a Me 3 Si-protected alkyne (1) in THF at $-100{ }^{\circ} \mathrm{C}$ [36]. The 50and 100-mer alkyne-end-functionalized st-PMMAs were synthesized by changing the feed ratios of the monomer to the initiator. The polymers that were obtained after quenching the reaction with acidic methanol showed controlled molecular weights, narrow MWDs (Figure 3A,C), and syndiotactic-rich enchainments $(m m / m r / r r=1 / 22 / 77)$.
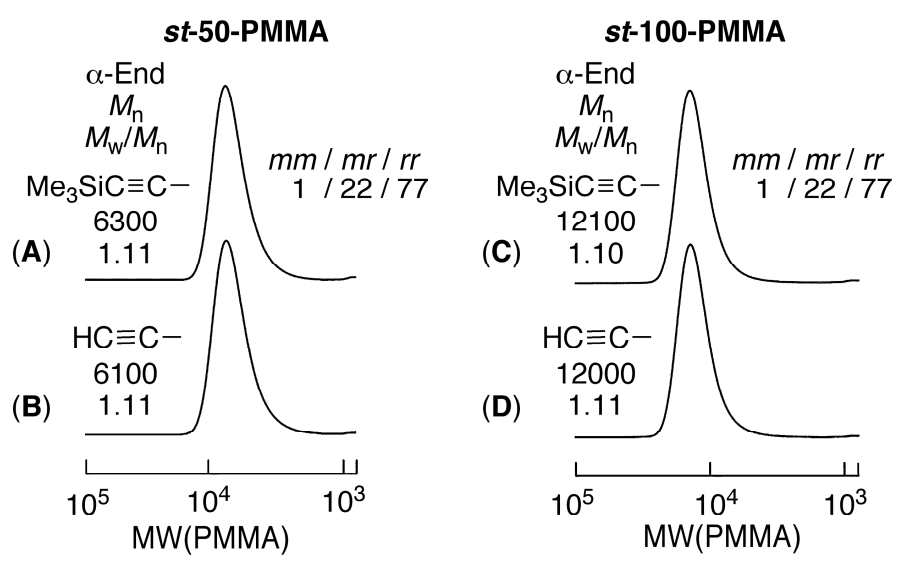

Figure 3. SEC curves of a series of st-PMMAs ((A,B): st-50, (C,D): st-100) obtained in DPHLi/1 in THF at $-100{ }^{\circ} \mathrm{C}$ and subsequent procedures: (A,B) Quenching the polymerization $\left([\mathrm{M}]_{0} /[\mathrm{DPHLi}]_{0} /[1]_{0}=\right.$ 924/34/51 or 1870/34/51 mM) with acidic methanol; (C,D) Deprotection of $\mathrm{Me}_{3} \mathrm{Si}$-group by $n$ - $\mathrm{Bu}_{4} \mathrm{NF}$ in THF at $0{ }^{\circ} \mathrm{C}\left(\left[\mathrm{Me}_{3} \mathrm{Si}-\right]_{0} /\left[n-\mathrm{Bu}_{4} \mathrm{NF}\right]_{0}=10 / 20 \mathrm{mM}\right)$. 
The ${ }^{1} \mathrm{H}$ NMR showed the presence of protected $\mathrm{Me}_{3} \mathrm{Si}-(h)$ and methylene protons $\left(g_{1}\right)$ adjacent to the alkyne function. The chain-end functionality of the protected alkyne group $\left(F_{\mathrm{n}}\left(\mathrm{C} \equiv \mathrm{C}-\mathrm{SiMe}_{3}\right)\right)$ was calculated from the ratio of $M_{\mathrm{n}}(\mathrm{SEC})$ to $M_{\mathrm{n}}(\mathrm{NMR})$, which was calculated from the peak intensity ratio of $g_{1}$ to the methyl ester protons (c) of the repeating MMA units (Figure 4A). They were close to unity for both of the polymers with different molecular weights $\left(F_{\mathrm{n}}=0.98\right.$ and 1.12 for $M_{\mathrm{n}}(\mathrm{SEC})=$ 6300 and 12100, respectively), indicating that the alkyne-functionalized $\alpha$-bromoisobutyric acid ester quantitatively initiates the syndiotactic living anionic polymerization via a metal-halogen exchange reaction in the presence of DPHLi to result in the well-defined alkyne-functionalized st-PMMA.

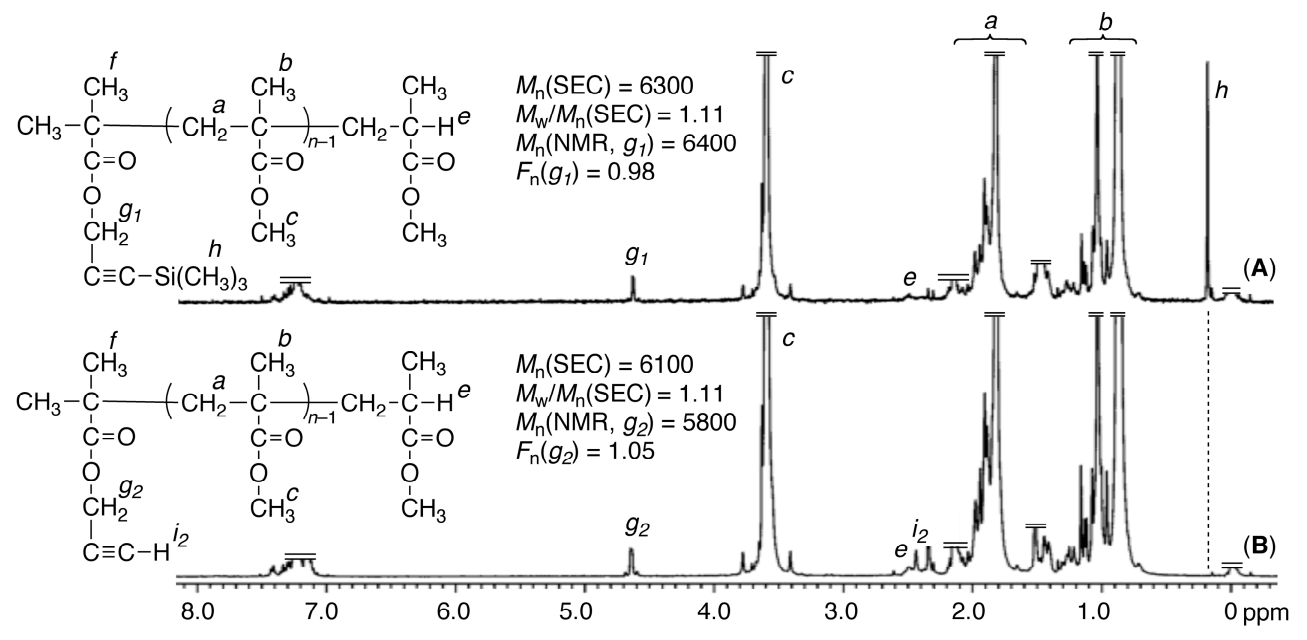

Figure 4. ${ }^{1} \mathrm{H}$ NMR spectra (in $\mathrm{CDCl}_{3}$ at $55{ }^{\circ} \mathrm{C}$ ) of st-50-PMMAs obtained in anionic polymerization of MMA with DPHLi $/ \mathbf{1}$ in THF at $-100^{\circ} \mathrm{C}$ and subsequent procedures: (A) Quenching the polymerization $\left([\mathrm{M}]_{0} /[\mathrm{DPHLi}]_{0} /[1]_{0}=924 / 34 / 51\right)$ with acidic methanol; (B) Deprotection of $\mathrm{Me}_{3}$ Si-group by $n$-Bu $\mathrm{Bu}_{4} \mathrm{NF}$ in THF at $0{ }^{\circ} \mathrm{C}\left(\left[\mathrm{Me}_{3} \mathrm{Si}-\right]_{0} /\left[n-\mathrm{Bu}_{4} \mathrm{NF}\right]_{0}=10 / 20 \mathrm{mM}\right)$.

The deprotection of the $\mathrm{Me}_{3} \mathrm{Si}$-group at the $\alpha$-end was conducted using tetrabutylammonium fluoride $\left(n-\mathrm{Bu}_{4} \mathrm{NF}\right)$ in THF at $0{ }^{\circ} \mathrm{C}$. There were almost no changes in the SEC curves with narrow MWDs after the deprotection (Figure 3B,D). The complete and successful deprotection was confirmed by the disappearance of the characteristic $\mathrm{Me}_{3} \mathrm{Si}$-protons $(h)$, and the appearance of a new peak that was assignable to the ethynyl proton $\left(i_{2}\right)$. The chain-end functionalities of the deprotected alkyne group $\left(F_{\mathrm{n}}(\mathrm{C} \equiv \mathrm{C}-\mathrm{H})\right)$ were similarly calculated from the methylene protons $\left(g_{2}\right)$ and were close to unity $\left(F_{\mathrm{n}}=1.05\right.$ and 1.04 for $M_{\mathrm{n}}(\mathrm{SEC})=6100$ and 12000 , respectively). These results show that st-PMMA with an alkyne group at the $\alpha$-chain end was successfully obtained by syndiotactic living anionic polymerization of MMA initiated via a metal-halogen exchange reaction between the protected alkyne-functionalized $\alpha$-bromoester and DPHLi followed by deprotection.

\subsection{Synthesis of it-b-st-Stereoblock PMMA via Copper-Catalyzed Azide-Alkyne Cycloaddition and Stereocomplexation}

Using two series of polymers with different molecular weights, i.e., it-PMMA- $\mathrm{N}_{3}\left(D P_{\mathrm{n}} \sim 25\right.$ and 50$)$ and st-PMMA-C $\equiv \mathrm{CH}\left(D P_{\mathrm{n}} \sim 50\right.$ and 100), CuAAC was conducted with four pairs of the polymers to produce it-b-st-stereoblock PMMAs with different block lengths (it-25-b-st-50, it-25-b-st-100, it-50-b-st-50, and it-50-b-st-100). The click reactions between it-PMMA-N $\mathrm{N}_{3}$ and st-PMMA-C $\equiv \mathrm{CH}$ were carried out in the presence of $\mathrm{CuSO}_{4}$ / sodium ascorbate in DMSO/ $\mathrm{H}_{2} \mathrm{O}(98 / 2)$ at $70{ }^{\circ} \mathrm{C}$, and the two polymers were mixed at the same molar ratio of the two functional groups using each $F_{\mathrm{n}}$ value. After the reaction, the SEC curves shifted to higher molecular weights (Figure 5A-D) although lower molecular weight peaks slightly remained, most probably due to the presence of a small amount of unfunctionalized prepolymers. The coupling products were further purified by reprecipitation in $n$-hexane to result in narrow SEC curves with higher molecular weights than the starting prepolymers. 
(A) it-25-b-st-50-PMMA

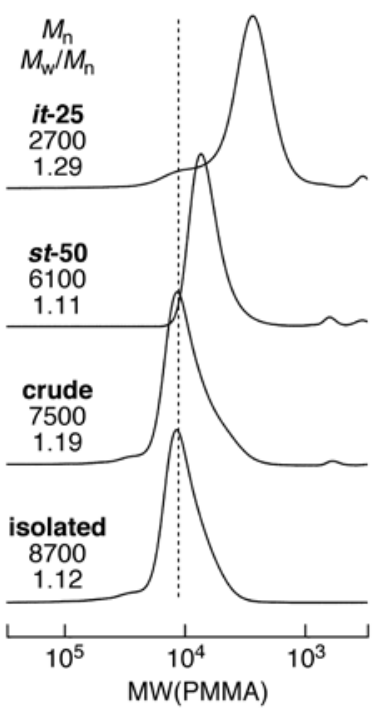

(B) it-25-b-st-100-PMMA

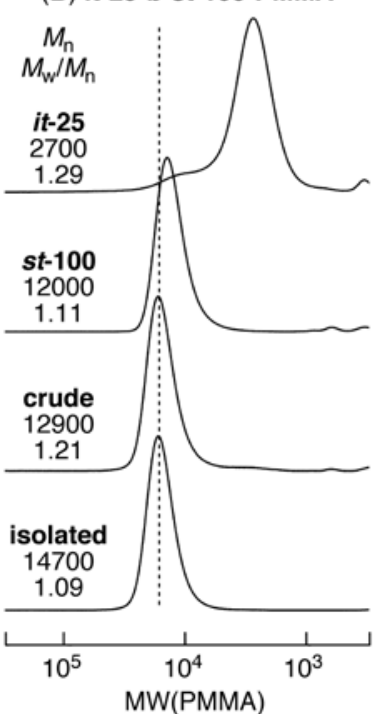

(C) it-50-b-st-50-PMMA

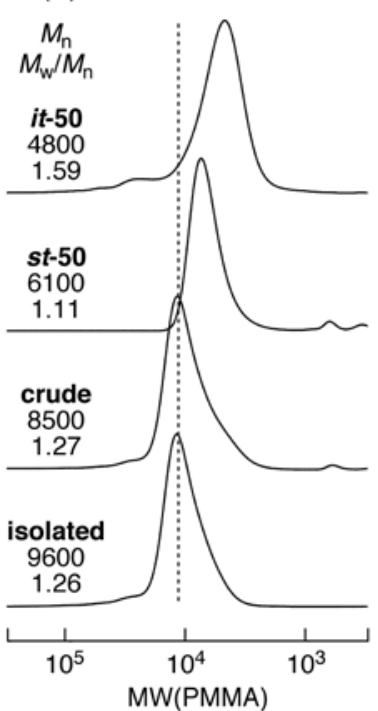

(D) it-50-b-st-100-PMMA

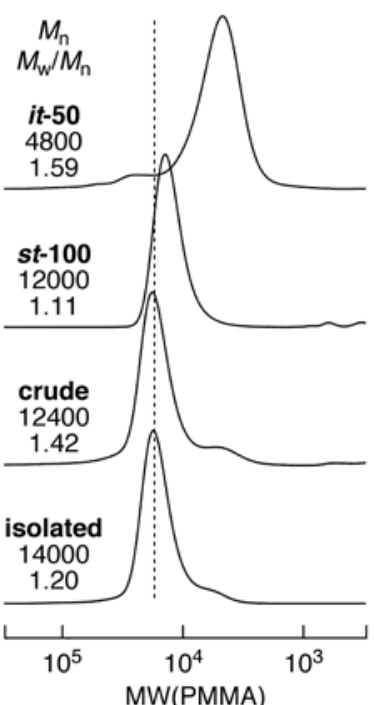

Figure 5. SEC curves of a series of it-PMMA-N 3 , st-PMMA-C $\equiv \mathrm{CH}$, and it- $b$-st-stereoblock PMMAs obtained via $\mathrm{CuAAC}$ in the presence of $\mathrm{CuSO}_{4} /$ sodium ascorbate in $\mathrm{DMSO} / \mathrm{H}_{2} \mathrm{O}(98 / 2)$ at $70{ }^{\circ} \mathrm{C}\left(\left[-\mathrm{N}_{3}\right]_{0} /[-\mathrm{C} \equiv \mathrm{CH}]_{0} /\left[\mathrm{CuSO}_{4}\right]_{0} /[\text { sodium ascorbate }]_{0}=15 / 15 / 5 / 20 \mathrm{mM}\right)$ as prepared and after reprecipitations. (A) it-25-b-st-50; (B) it-25-b-st-100; (C) it-50-b-st-50; (D) it-50-b-st-100.

In the ${ }^{1} \mathrm{H}$ NMR spectrum of the obtained polymers, new peaks for the triazole-ring methine $(j)$ at $7.8 \mathrm{ppm}$ and the adjacent methylene $\left(g_{4}\right)$ protons at $5.2 \mathrm{ppm}$ appeared due to the reaction of the alkyne group at the $\alpha$-end of st-PMMA with the azide $\omega$-terminal of it-PMMA (Figure 6C). Although a small peak for methylene protons $\left(g_{2}\right)$ was observed due to the unreacted remaining st-PMMA prepolymers, the purity of the block polymers was relatively high (90\%). The purity was calculated from the peak intensity ratio, $g_{4} /\left(g_{2}+g_{4}\right)$. The ${ }^{13} \mathrm{C}$ NMR spectrum of the carbonyl groups of the obtained coupling products (Figure 6F) was a weighed superimposition of the two spectra of it-PMMA (Figure 6D) and st-PMMA (Figure 6E). The block length ratio was calculated from the tacticities of both the it-PMMA and st-PMMA prepolymers $\left(m m_{\text {total }}=x_{i t} \times m m_{i t}+x_{s t} \times m m_{s t}, r r_{\text {total }}=x_{i t} \times r r_{i t}+x_{s t} \times r r_{s t}\right)$ and was $x_{i t}: x_{s t}=0.28: 0.72$, which was close to the theoretical value, $x_{i t}: x_{s t}=0.31: 0.69$, assuming the formation of $i t$ - $b$-st-stereoblock PMMA with the expected block length. These results indicate that it-b-st-stereoblock PMMAs with various block lengths were efficiently synthesized via CuAAC between the azide-capped it-PMMA and alkyne-capped st-PMMA (Table 1). 


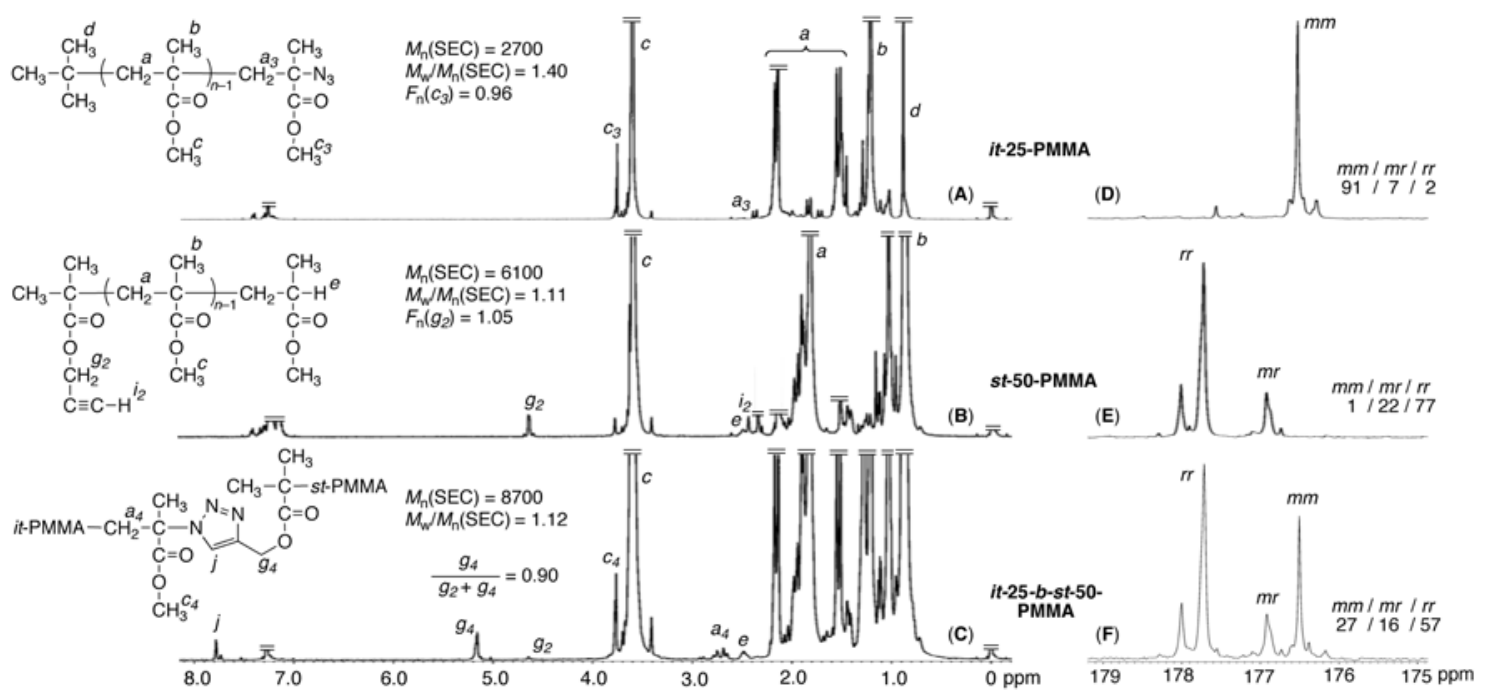

Figure 6. ${ }^{1} \mathrm{H}$ and ${ }^{13} \mathrm{C}$ NMR spectra (in $\mathrm{CDCl}_{3}$ at $55{ }^{\circ} \mathrm{C}$ ) of it-25-, st-50-, and it-25-b-st-50-PMMAs: (A,D) it-25-PMMA-N $\mathrm{N}_{3}$ obtained in isotactic anionic polymerization of MMA followed by chlorination and azidation; (B,E) st-50-PMMA-C $\equiv \mathrm{CH}$ obtained in syndiotactic anionic polymerization of MMA followed by deprotection of $\mathrm{Me}_{3}$ Si-group; (C,F) it-25- $b$-st-50-PMMA obtained via CuAAC between it-25-PMMA- $\mathrm{N}_{3}$ and st-50-PMMA-C $\equiv \mathrm{CH}$ in the presence of $\mathrm{CuSO}_{4} /$ sodium ascorbate in DMSO $/ \mathrm{H}_{2} \mathrm{O}$ $(98 / 2)$ at $70{ }^{\circ} \mathrm{C}\left(\left[-\mathrm{N}_{3}\right]_{0} /[-\mathrm{C} \equiv \mathrm{CH}]_{0} /\left[\mathrm{CuSO}_{4}\right]_{0} /[\text { sodium ascorbate }]_{0}=15 / 15 / 5 / 20 \mathrm{mM}\right)$.

Table 1. Molecular weight and tacticity of prepolymers and it-b-st PMMAs.

\begin{tabular}{|c|c|c|c|c|c|c|c|c|c|}
\hline Code & $M_{\mathrm{n}}(i t)$ & $m m / m r / r r(i t)$ & $M_{\mathrm{n}}(s t)$ & $m m / m r / r r(s t)$ & $\underset{(i t-b-s t)}{M_{\mathrm{n}}}$ & $\begin{array}{l}M_{\mathrm{w}} / M_{\mathrm{n}} \\
(i t-b-s t)\end{array}$ & $\begin{array}{c}m m / m r / r r \\
(i t-b-s t)\end{array}$ & it-/st-Calcd & it-/st-NMR \\
\hline$i t-25-b$-st-50 & 2700 & $91 / 7 / 2$ & 6100 & $1 / 22 / 77$ & 8700 & 1.12 & $27 / 16 / 57$ & $31 / 69$ & $28 / 72$ \\
\hline$i t-25-b-s t-100$ & 2700 & $91 / 7 / 2$ & 12000 & $1 / 22 / 77$ & 14700 & 1.09 & $18 / 20 / 62$ & $18 / 82$ & $19 / 81$ \\
\hline$i t-50-b-s t-100$ & 4800 & $92 / 7 / 1$ & 12000 & $1 / 22 / 77$ & 14000 & 1.20 & $27 / 16 / 57$ & $29 / 71$ & $32 / 68$ \\
\hline
\end{tabular}

The stereocomplexation of these stereoblock polymers was evaluated in $\mathrm{CH}_{3} \mathrm{CN}$ by measuring the transmittance of the solutions $(100 \mathrm{mg} / \mathrm{mL})$. Figure 7 plots the relative values as compared to the transmittance at $70{ }^{\circ} \mathrm{C}$. The solutions gradually became turbid as the temperature decreased, and the transmittance of the samples approached $0 \%$, except for $i t-25-b$-st-100. Furthermore, the solution of $i t-50-b$-st-100 formed a gel, whereas no gelation occurred in the other solutions. 


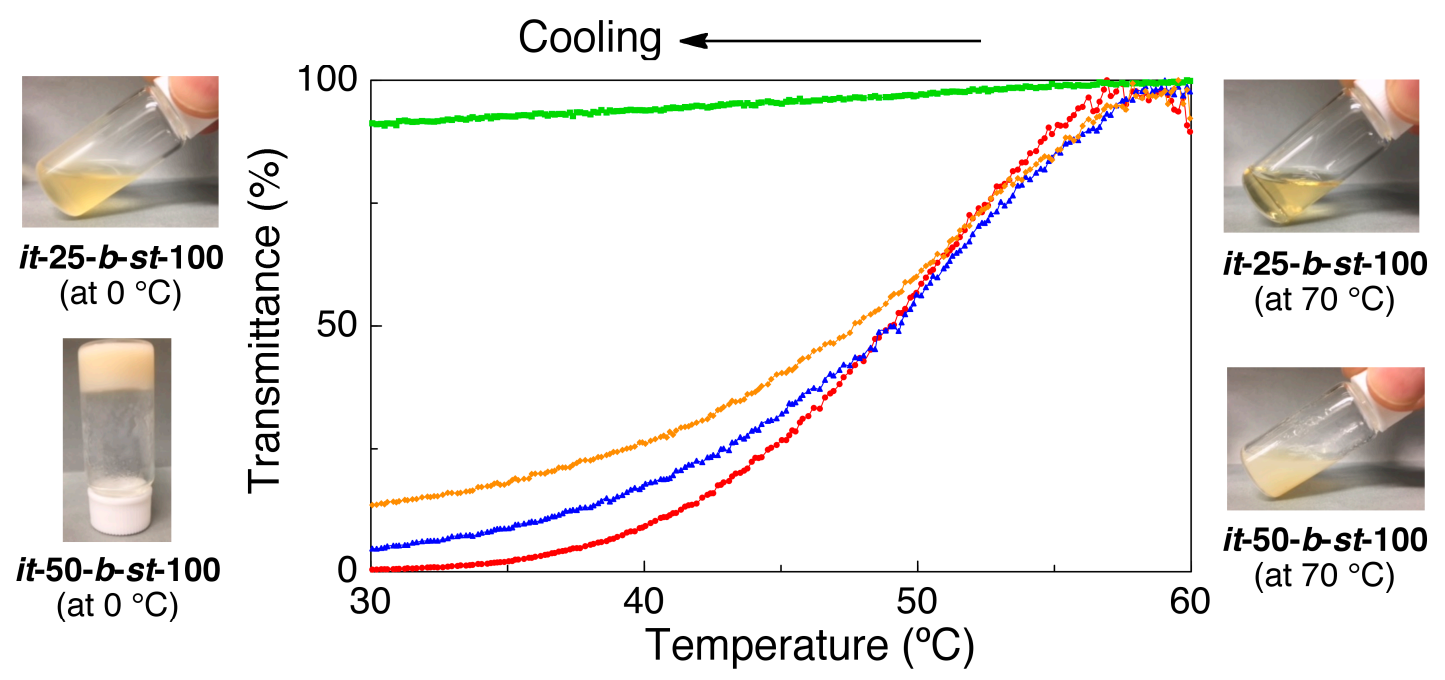

Figure 7. Relative transmittance (wavelength $=500 \mathrm{~nm}$ ) of a series of SEC curves of solutions of it-b-st-stereoblock PMMAs in $\mathrm{CH}_{3} \mathrm{CN}(100 \mathrm{mg} / \mathrm{mL})$ with varying temperatures at cooling rate of $1{ }^{\circ} \mathrm{C} / \mathrm{min}$ : Orange, it-25- $b$-st-50; Green, it-25- $b$-st-100; Blue, it-50-b-st-50; Red, it-50-b-st-100.

According to the most recent studies on stereocomplexation, two it-PMMA chains intermolecularly aggregate to form a double helix, which is surrounded by a single helix of st-PMMA to form a unique triple helix-like structure [2,7]. In this model, the degree of polymerization of the outer st-PMMA chain is double that of the inner it-PMMA chain (it:st =1:2), while the MMA unit ratio of the total it-PMMA chains and st-PMMA chain is 1:1 because of the two it-chains per st-chain in the stereocomplex.

If this model is applied to it-b-st-stereoblock PMMA, the it-segments in two block polymer chains can form a double helix to result in a supramolecular structure, e.g., a Y-shape containing two independent single helixes of st-segments that are connected to each it-segment in the double helix of the it-segments. The it-double helix segment in the Y-shape supramolecule can be incorporated into a single st-helix of another Y-shape molecule to induce further intermolecular associations and finally result in a gel. Among the four it-b-st-stereoblock PMMAs with different block lengths, the it-50-b-st-100 PMMA has the most suitable ratio (it:st $=1: 2$ ) of block lengths for this stereocomplexation model, and can easily result in a gel, whereas the total chain length of it-25-b-st-50 PMMA is shorter and less efficient for gel formation, in spite of the suitable ratio ( $i t: s t=1: 2$ ). Irrespective of the longer st-segment in it-25-b-st-100 PMMA, the solution was nearly transparent even at low temperatures, suggesting a low degree of association or intramolecular association due to the long st-segment in comparison to that with the short it-segment ( $i t: s t=1: 4)$.

To investigate the effects of the block structure on the stereocomplexation, the four precursor non-block polymers, i.e., it-25- or it-50-PMMA and st-50- or st-100-PMMA, were mixed together at the same molar ratio in $\mathrm{CH}_{3} \mathrm{CN}$. All of the solutions became turbid upon decreasing the temperature. However, no gelation occurred for any of the it- and st-mixtures at $100 \mathrm{mg} / \mathrm{mL}$. Only the mixture of it-50- and st-100-PMMAs formed a gel at a higher concentration, i.e., $200 \mathrm{mg} / \mathrm{mL}$. These results indicate that connecting the it- and st-PMMA segments via a covalent linkage in it-b-st-PMMA enhances gelation via stereocomplexation.

To further confirm the stereocomplexation, the polymers were analyzed by DSC. The precursor linear it-50- and st-100-PMMA showed $T_{\mathrm{g}}$ around 35 and $110{ }^{\circ} \mathrm{C}$, respectively. The sample of it-50-b-st-100 PMMA, which was obtained by evaporating $\mathrm{CH}_{3} \mathrm{CN}$ from the solution and dried in vacuo, showed melting temperatures at 166 and $185^{\circ} \mathrm{C}$, which were slightly higher than those that were reported to the stereocomplexes of linear it- and st-PMMAs [33]. These results also support that the it-b-st-steroblock PMMA forms the stereocomplex. 


\section{Conclusions}

The isotactic-syndiotactic stereoblock PMMAs were efficiently prepared via CuAAC between end-functionalized isotactic and syndiotactic PMMAs that were obtained by stereospecific living anionic polymerization of MMA in combination with a metal-halogen exchange reaction for initiation and a halogenation reaction for termination. The reversible transformation between the halide and living anionic chain end, which was used for initiation or termination, enables efficient end-functionalization of stereoregular polymethacrylates, which can be further utilized for the construction of structurally controlled polymers and supramolecular architectures.

Acknowledgments: This work was partially supported by a Grant-in-Aid for Scientific Research (A) (No. 26248032) for K.S. by the Japan Society for the Promotion of Science, and Program for Leading Graduate Schools "Integrative Graduate Education and Research Program in Green Natural Sciences".

Author Contributions: Naoya Usuki, Kotaro Satoh and Masami Kamigaito conceived and designed the experiments; Naoya Usuki performed the experiments; Naoya Usuki, Kotaro Satoh and Masami Kamigaito wrote the paper.

Conflicts of Interest: The authors declare no conflict of interest.

\section{References}

1. Lutz, J.-F.; Lehn, J.-M.; Meijer, E.W.; Matyjaszewski, K. From precision polymers to complex materials and systems. Nat. Rev. Mater. 2016, 1, 16024. [CrossRef]

2. Yashima, E.; Ousaka, N.; Taura, D.; Shimomura, K.; Ikai, T.; Maeda, K. Supremolecular helical systems: Helical assembles of small molecules, foldamers, and polymers with chiral amplification and their functions. Chem. Rev. 2016, 116, 13752-13990. [CrossRef] [PubMed]

3. Fox, T.G.; Garrett, B.S.; Goode, W.E.; Gratch, S.; Kincaid, J.F.; Spell, A.; Stroupe, J.D. Crystalline polymers of methyl methacryalte. J. Am. Chem. Soc. 1958, 80, 1768-1769. [CrossRef]

4. Liquori, A.M.; Anzuino, G.; Coiro, V.M.; D'Alagni, M.; De Santis, P.; Savino, M. Complementary stereospecific interaction between isotactic and syndiotactic polymer molecules. Nature 1965, 206, 358-362. [CrossRef]

5. Schomaker, E.; Challa, G. Complexation of stereoregular poly(methyl methacryalte). 14. The basic structure of the stereocomplex of isotactic and syndiotactic poly(methyl methacryalte). Macromolecules 1989, 22, 3337-3341. [CrossRef]

6. Spěváček, J.; Schneider, B. Aggregation of stereoregular poly(methyl methacryalte). Adv. Colloid Interface Sci. 1987, 27, 81-150. [CrossRef]

7. Kumaki, J.; Kawauchi, T.; Okoshi, K.; Kusanagi, H.; Yashima, E. Supramolecular helical structure of the stereocomplex composed of complementary isotactic and syndiotactic poly(methyl methacrylate)s as revealed by atomic force microscopy. Angew. Chem. Int. Ed. 2007, 46, 5348-5351. [CrossRef] [PubMed]

8. Kumaki, J.; Kawauchi, T.; Ute, K.; Kitayama, T.; Yashima, E. Molecular weight recognition in the multiple-stranded helix of a synthetic polymer without specific monomer-monomer interaction. J. Am. Chem. Soc. 2008, 130, 6373-6380. [CrossRef] [PubMed]

9. Kawauchi, T.; Kitaura, A.; Kumaki, J.; Kusanagi, H.; Yashima, E. Helix-sense-controlled synthesis of optically active poly(methyl methacrylate) stereocomplexes. J. Am. Chem. Soc. 2008, 130, 11889-11891. [CrossRef] [PubMed]

10. Christofferson, A.J.; Yiapanis, G.; Ren, J.M.; Qiao, G.G.; Satoh, K.; Kamigaito, M.; Yarovsky, I. Molecular mapping of poly(methyl methacrylate)super-helix stereocomplexes. Chem. Sci. 2015, 6, 1370-1378. [CrossRef]

11. Sugaya, H.; Sakai, Y. Polymethylmethacryalte: From polymer to dialyzer. Contrib. Nephrol. 1998, 125, 1-8.

12. Brinkhuis, R.H.G.; Schouten, J.A. Thin-film behavior of poly(methy1 methacrylates). 6. Monolayer phase behavior in relation to stereocomplexation in mixed monolayers of i- and s-PMMA. Macromolecules 1993, 26, 2514-2519. [CrossRef]

13. Serizawa, T.; Hamada, K.; Kitayama, T.; Fujimoto, N.; Hatada, K.; Akashi, M. Stepwise stereocomplex assembly of stereoregular poly(methyl methacrylate)s on a substrate. J. Am. Chem. Soc. 2000, 122, 1891-1899. [CrossRef] 
14. Hamada, K.; Serizawa, T.; Kitayama, T.; Fujimoto, N.; Hatada, K.; Akashi, M. Stepwise stereocomplex assembly of isotactic poly(methyl methacrylate) and syndiotactic poly(alkyl methacrylate)s on surfaces. Langmuir 2001, 17, 5513-5559. [CrossRef]

15. Serizawa, T.; Hamada, K.; Akashi, M. Polymerization within a molecular-scale stereoregular template. Nature 2004, 429, 52-55. [CrossRef] [PubMed]

16. Kamei, D.; Ajiro, H.; Akashi, M. Specific recognition of syndiotactic poly(methacrylic acid) in porous isotactic poly(methyl methacrylate) thin films based on the effects of stereoregularity, temperature, and solvent. J. Polym. Sci. Part A 2010, 48, 3561-3567. [CrossRef]

17. Kawauchi, T.; Kumaki, J.; Kitaura, A.; Okoshi, K.; Kusanagi, H.; Kobayashi, K.; Sugai, T.; Shinohara, H.; Yashima, E. Encapsulation of fullerenes in a helical PMMA cavity leading to a robust processable complex with a macromolecular helicity memory. Angew. Chem. Int. Ed. 2008, 47, 515-519. [CrossRef] [PubMed]

18. Qi, S.; Iida, H.; Liu, L.; Irle, S.; Hu, W.; Yashima, E. Electrical switching behavior of a [60]fullerene-based molecular wire encapsulated in a syndiotactic poly(methyl methacrylate) helical cavity. Angew. Chem. Int. Ed. 2013, 52, 1049-1053. [CrossRef] [PubMed]

19. Ousaka, N.; Mamiya, F.; Iwata, Y.; Nishimura, K.; Yashima, E. "Helix-in-helix" superstructure formation through encapsulation of fullerene-bound helical peptides within a helical poly(methyl methacrylate) Cavity. Angew. Chem. Int. Ed. 2017, 56, 791-795. [CrossRef] [PubMed]

20. Hatada, K. Stereoregular uniform polymers. J. Polym. Sci. Part A 1999, 37, 245-260. [CrossRef]

21. Hatada, K.; Kitayama, T. Structurally controlled polymerizations of methacrylates and acrylates. Polym. Int. 2000, 49, 11-47. [CrossRef]

22. Doherty, M.A.; Hogen-Esch, T.E. Synthesis of a stereoblock poly(methyl methacrylate). Makromol. Chem. 1986, 187, 61-69. [CrossRef]

23. Kitayama, T.; Fujimoto, N.; Yanagida, T.; Hadata, K. Synthesis of stereoblock poly(methyl methacrylate) via transformation of isotactic-specific living polymer anion to syndiotactic-specific anion. Polym. Int. 1994, 33, 165-170. [CrossRef]

24. Hatada, K.; Nshiura, T.; Kitayama, T.; Ute, K.; Hirotani, S. Preparation of uniform stereoblock poly(methyl methacrylate). Polym. J. 1996, 28, 185-188. [CrossRef]

25. Nshiura, T.; Kitayama, T.; Hatada, T. Intra- and Intermolecular Stereocomplex Formation of Uniform Stereoblock Poly(methyl methacrylate). Polym. J. 1996, 28, 1021-1023. [CrossRef]

26. Hatada, K.; Kitayama, T.; Ute, K.; Nshiura, T. Preparation of uniform stereoregular polymer, stereoblock polymer and copolymer of methacrylate, and their stereocomplex formation. Macromol. Symp. 1998, 132, 221-230. [CrossRef]

27. Nishiura, T.; Abe, Y.; Kitayama, T. Uniform poly(methyl methacrylate) stereostars: Synthesis, separation and stereocomplex formation. Polym. J. 2010, 42, 868-874. [CrossRef]

28. Mariott, W.R.; Escudé, N.C.; Chen, E.Y.-X. Stereoregular P(MMA)-clay nanocomposites by metallocene catalysts: In situ synthesis and stereocomplex formation. J. Polym. Sci. Part A 2007, 45, 2581-2592. [CrossRef]

29. Escudé, N.C.; Ning, Y.; Chen, E.Y.-X. In situ stereocomplexing polymerization of methyl methacrylate by diastereospecific metallocene catalyst pairs. Polym. Chem. 2012, 3, 3247-3255. [CrossRef]

30. Vidal, F.; Falivene, L.; Caporaso, L.; Caballo, L.; Chen, E.Y.-X. Robust cross-linked stereocomplexes and $\mathrm{C}_{60}$ inclusion complexes of vinyl-functionalized stereoregular polymers derived from chemo/stereoselective coordination polymerization. J. Am. Chem. Soc. 2016, 138, 9533-9547. [CrossRef] [PubMed]

31. Wang, Y.; Bailey, T.S.; Hong, M.; Chen, E.Y.-X. Stereoregular brush polymers and graft copolymers by chiral zirconocene-mediated coordination polymerization of P3HT macromers. Polymers 2017, 9, 139. [CrossRef]

32. Goh, T.K.; Tan, J.F.; Guntari, S.N.; Satoh, K.; Blencowe, A.; Kamigaito, M.; Qiao, G.G. Nano-to-macroscale poly(methyl methacrylate) stereocomplex sssemblies. Angew. Chem. Int. Ed. 2009, 48, 8707-8711. [CrossRef] [PubMed]

33. Ren, J.M.; Satoh, K.; Goh, T.K.; Blencowe, A.; Nagai, K.; Ishitake, K.; Christofferson, A.J.; Yiapanis, G.; Yarovsky, I.; Kamigaito, M.; et al. Stereospecific cyclic poly(methyl methacrylate) and its topology-guided hierarchically controlled supramolecular sssemblies. Angew. Chem. Int. Ed. 2014, 53, 459-464. [CrossRef]

34. Ren, J.M.; Subbiah, J.; Zhang, B.; Ishitake, K.; Satoh, K.; Kamigaito, M.; Qiao, G.G.; Wong, E.H.H.; Wong, W.W.H. Fullerene peapod nanoparticles as an organic semiconductor-electrode interface layer. Chem. Commun. 2016, 52, 3356-3359. [CrossRef] [PubMed] 
35. Ren, J.M.; Ishitake, K.; Satoh, K.; Blencowe, A.; Fu, Q.; Wong, E.H.H.; Kamigaito, M.; Qiao, G.G. Stereoregular high-density bottlebrush polymer and its organic nanocrystal stereocomplex through triple-helix formation. Macromolecules 2016, 49, 788-795. [CrossRef]

36. Usuki, N.; Satoh, K.; Kamigaito, M. Synthesis of syndiotactic macrocyclic poly(methyl methacrylate) via transformation of the growing terminal in stereospecific anionic polymerization. Macromol. Chem. Phys. 2017, 218, 1700041. [CrossRef]

37. Kohsaka, Y.; Kurata, T.; Kitayama, T. End-functional stereoregular poly(methyl methacrylate) with clickable $\mathrm{C}=\mathrm{C}$ bonds: Facile synthesis and thiol-ene reaction. Polym. Chem. 2013, 4, 5043-5047. [CrossRef]

38. Kohsaka, Y.; Kurata, T.; Yamamoto, K.; Ishihara, S.; Kitayama, T. Synthesis and post-polymerization reaction of end-clickable stereoregular polymethacrylates via termination of stereospecific living anionic polymerization. Polym. Chem. 2015, 6, 1078-1087. [CrossRef]

39. Kohsaka, Y.; Yamamoto, K.; Ishihara, S.; Kitayama, T. Stereoregular poly(methyl methacrylate) with double-clickable-end: Synthesis and click reaction. Polym. Chem. 2015, 6, 3601-3607. [CrossRef]

40. Nishioka, A.; Watanabe, H.; Abe, K.; Sono, Y. Grignard reagent-catalyzed polymerization of methyl methacrylate. J. Polym. Sci. 1960, 48, 241-272. [CrossRef]

41. Liquiori, A.M.; Anzuino, G.; D'Alagni, M.; Vitagliano, V.; Costantino, L. Identification of a stereoblock poly(methyl methacrylate) sample with a stereocomplex. J. Polym. Sci. Part A-2 1968, 6, 509-516. [CrossRef]

42. Dixit, S.S.; Deshpande, A.B.; Anand, L.C.; Kapur, S.L. Stereoblock polymerization of methyl methacrylate with $\mathrm{VOCl}_{3}-\mathrm{Al}\left(\mathrm{C}_{2} \mathrm{H}_{5}\right)_{3}$ catalyst system. J. Polym. Sci. Part A-1 1969, 7, 1973-1982. [CrossRef]

43. Dixit, S.S.; Deshpande, A.B.; Kapur, S.L. Kinetics and mechanism of polymerization yielding stereoblock poly(methyl methacrylate) with $\mathrm{VCl}_{4}-\mathrm{Al}\left(\mathrm{C}_{2} \mathrm{H}_{5}\right)_{3}$ catalyst system. J. Polym. Sci. Part A-1 1970, 8, 1289-1297. [CrossRef]

44. Miyamoto, T.; Inagaki, H. The stereocomplex formation in poly(methyl methacrylate) and the stereospecific polymerization of its monomer. Polym. J. 1970, 1, 46-54. [CrossRef]

45. Buter, R.; Tan, Y.T.; Challa, G. Characterization of stereoblock polymers of poly(methyl methacrylate) by thin-layer chromatography. Polymer 1973, 14, 171-172. [CrossRef]

46. Miyamoto, T.; Tomoshige, S.; Inagaki, H. Separation of isotactic and syndiotactic poly(methyl methacrylate) by a competitive adsorption method. Polym. J. 1974, 6, 564-570. [CrossRef]

47. Allen, P.E.M.; Bateup, B.O. Polymerization of methylmethacrylate by organometallic compounds-VIII. Initiation by $n-, i-, s$ - or $t$-butylmagnesium compounds-Evidence for an eneidic pseudoanionic mechanism. Eur. Polym. J. 1978, 14, 1001-1010. [CrossRef]

48. Allen, P.E.M.; Mair, C. Isotactic and stereoblock poly(methyl methacrylates) produced by butylmagnesium initiators. Eur. Polym. J. 1984, 20, 697-705. [CrossRef]

49. Allen, P.E.M.; Host, D.M.; Truong, V.T.; Williams, D.R.G. Some physical and mechanical properties of isotactic-atactic poly(methyl methacrylate) blends and stereoblocks. Eur. Polym. J. 1985, 21, 603-610. [CrossRef]

50. Aoshima, H.; Satoh, K.; Kamigaito, M. Direct mechanistic transformations from isotactic or syndiotactic living anionic polymerizations of methyl methacrylate into metal-catalyzed living radical polymerizations. ACS Macro Lett. 2013, 2, 72-76. [CrossRef]

51. Hatada, K.; Ute, K.; Tanaka, K.; Kitayama, T.; Okamoto, Y. Preparation of highly isotactic poly(methyl methacrylate) of low polydispersity. Polym. J. 1985, 17, 977-980. [CrossRef]

52. Hatada, K.; Ute, K.; Tanaka, K.; Okamoto, Y.; Kitayama, T. Living and highly isotactic polymerization of methyl methacrylate by $t-\mathrm{C}_{4} \mathrm{H}_{9} \mathrm{MgBr}$ in toluene. Polym. J. 1986, 18, 1037-1047. [CrossRef]

53. Cao, Z.-K.; Okamoto, Y.; Hatada, K. Synthesis of syndiotactic poly(methyl methacrylate)s with Bulky Alkyllithiums. Koubunshi Ronbunshu 1986, 12, 857-861. [CrossRef]

(C) 2017 by the authors. Licensee MDPI, Basel, Switzerland. This article is an open access article distributed under the terms and conditions of the Creative Commons Attribution (CC BY) license (http://creativecommons.org/licenses/by/4.0/). 